\title{
Maximal Bite Force and its Association with Temporomandibular Disorders
}

\author{
Tatiana PEREIRA-CENCI ${ }^{1}$ \\ Luciano José PEREIRA ${ }^{1}$ \\ Maximiliano Sérgio CENCI ${ }^{1}$ \\ Wellington Cardoso BONACHELA ${ }^{2}$ \\ Altair Antoninha DEL BEL CURY ${ }^{1}$ \\ ${ }^{1}$ School of Dentistry of Piracicaba, State University of Campinas, Piracicaba, SP, Brazil \\ ${ }^{2}$ School of Dentistry of Bauru, University of São Paulo, Bauru, SP, Brazil
}

\begin{abstract}
Individuals with temporomandibular disorders (TMD) are expected to have decreased maximum bite forces (MBF). This way, this study compared the MBF in subjects with TMD to a control group and also evaluated its association with age, gender, height and weight. Forty healthy adults with complete natural dentition divided into four groups according to gender and presence or absence of TMD signs/symptoms (based on the Research Diagnostic Criteria - RDC) underwent a MBF test with a gnathodynamometer in molar and incisal areas. Statistical analysis was performed by ANOVA and Student-Newman-Keuls test ( $p=0.05)$, and the relationship between age, gender, weight, height and MBF was verified by Pearson's correlation test. There were no differences in MBF results between TMD and control groups ( $>>0.05$ ). Female subjects exhibited lower MBF than male and MBF for the anterior area was lower than that for posterior area $(\mathrm{p}<0.05)$. Significant correlation was found between MBF and weight in TMD subjects ( $<<0.05)$, except for the anterior area in female subjects. There was a positive correlation between MBF and height in TMD male subjects ( $<<0.05$ ). Within the limitations of this study, it is possible to conclude that bite force was not affected by TMD. Correlation between MBF and weight in TMD subjects and between MBF and height in TMD male subjects was observed.
\end{abstract}

Key Words: maximal bite force, age, gender, height, weight, temporomandibular disorders.

\section{INTRODUCTION}

The term “temporomandibular disorders” (TMD) refers to symptoms and signs associated with pain and functional and structural disturbances of the masticatory system, especially the temporomandibular joints (TMJ) and the masticatory muscles (1). The bite force has an influence on muscle efficiency and development of the masticatory function (2). It tends to increase with the need to chew (3), with body weight and body height but decreases with changes in dentition and also in the presence of pain $(1,4)$. Based on these statements, individuals with TMD are expected to have decreased maximum bite forces. However, there is no consensus in the literature whether individuals with a diseased TMJ have decreased or increased maximum bite forces in relation to healthy subjects $(5,6)$.

Moreover, clinicians have presented a rising interest in bite force with regard to its potential influence on the development of the masticatory system, in order to predict eventual functional limitation as a consequence of TMD. Therefore, it is of great importance to elucidate whether there is an influence of TMD in subjects' bite force, as well to examine the gender differences, and its relationship with physical characteristics, such as age, height and weight (2).

The purpose of this study was to measure MBF values in molar and incisor regions between subjects with and without signs and symptoms of TMD and to study the possible association between gender, height, weight and maximal bite force. An additional aim was to investigate whether there was any difference in maximal 
bite force after performing a masticatory test.

\section{MATERIAL AND METHODS}

\section{Participants' Sellection}

One hundred and sixty adults with complete natural dentition were recruited and examined from faculty members and students of the School of Dentistry of Bauru, University of São Paulo, Brazil. The inclusion criteria were based on the Research Diagnostic Criteria (7) and the TMD group was selected according to the following criteria, without distinction within RDC diagnosis as follows: (i) good general health, (ii) TMD with pain (VAS - visual analogical scale - higher than 50 $\mathrm{mm}$ ). Forty volunteers were selected (mean age 25.42 \pm 5.38) and assigned to 4 groups: Group 1: 14 female with no TMD signs/symptoms (control); Group 2: 7 male with no TMD signs/symptoms (control); Group 3: 11 female with TMD signs/symptoms; Group 4: 8 male with TMD signs/symptoms. All the participants signed informed consent forms after the nature of the procedures and the possible discomforts and risks had been fully explained. The local Ethics Committee approved the protocol.

\section{Maximal Bite Force}

In this study, MBF was measured using a gnathodynamometer (Kratos Industrial Equipment Ltd., SP, Brazil). The MBF was obtained placing the gnathodynamometer transducer plates between the central incisors for the anterior MBF evaluation and between first molars unilaterally (chosen as the preferred side of mastication related by the volunteer) to determine posterior MBF. Each subject was standing with a relaxed head posture, keeping Frankfort horizontal plane approximately parallel to the floor. The transducer was also maintained parallel to Frankfort horizontal plane. One blind examiner (who did not know whether or not the subject had TMD) carried out the test.

Data were collected in a single session and each subject clenched three times before and after a masticatory test: central incisors and first molars, resting 5 to $10 \mathrm{~s}$ between each bite. The masticatory test was carried out to verify whether the TMD or control subjects were harmed by the masticatory activity (e.g. decreased MBF) and to confirm that only patients presenting TMD with pain were selected. Subjects were first asked to clench on the plates, as hard as possible. Then, they were asked to chew on 10 carrot samples (one by one) normally $\left(1.0 \times 1.0 \mathrm{~cm} ; 20^{\circ} \mathrm{C}\right)$ and afterwards, the volunteers were asked to swallow the bolus at the point when swallowing would have normally been triggered. They were asked to clench again on the plates as hard as possible. The interocclusal separation provided by the gnathodynamometer thickness was $14 \mathrm{~mm}$ when the test was carried out.

\section{Statistical Analysis}

Statistical analysis of differences in MBF means before and after mastication test in anterior and posterior areas inter and intra-groups was performed with ANOVA and Student-Newman-Keuls pos-hoc test, and the association between MBF and age, weight and height was verified with Pearson's correlation test. The significance level was set at $5 \%$.

\section{RESULTS AND DISCUSSION}

There were no differences in MBF results between TMD and control groups, either before or after masticatory test ( $p>0.05$ ) (Fig. 1), confirming that there was no decrease in muscle force after chewing hard samples (carrot). As the masticatory test was carried out to verify if the TMD subjects were harmed by this activity, the possible reason might be the fact that TMD may cause pain but not necessarily causes diminished function. It means that, even with pain, subjects still did efforts to chew the hard sample as usual; however hard food seems to be avoided by majority of the patients. In fact, the referred test may not have been enough to lead to a hyperactivation (e.g. evoking adaptive motor reactions and inhibition during forceful biting), and consequently, the pain caused by the test was mild to cause a decrease in bite force or fatigue in the muscles.

Female subjects exhibited lower MBF than male and MBF for anterior area was lower than posterior area $(p<0.05)$. Significant correlation was found between MBF and weight in TMD subjects ( $\mathrm{p}<0.05)$, except for anterior area in female subjects (Fig. 1). There was a positive correlation between MBF and height in TMD male subjects $(\mathrm{p}<0.05)$.

This study was designed to eliminate confusing variables, fixing the participants' age, weight and height 
range. Pain appears to be relatively common, occurring in approximately $10 \%$ of the population over age 18 and primarily a condition of young and middle-aged adults (8) (11.87\% from the overall 160 subjects in our study). As Tortopidis et al. (9) reported a difference in values measured in different sessions, data were collected in a single session. According to Manns et al. (10), maximal clenching force is greatest at an increased vertical dimension of occlusion of 10-20 mm. The interocclusal separation was approximately $14 \mathrm{~mm}$ when the test was carried out in the posterior or anterior area.

Individuals with various forms of TMD have been reported to have either a decrease $(9,11,12)$ or increase (13) in bite force although this was not found in the present study, where no difference in TMD subjects was found. The association between the presence of TMD and reduced MBF is contradictory in the literature and may be dependent on the severity of the TMD in the given sample (14-17). Our results agree with those of previous studies $(2,18,19)$, where no association between TMD and bite force was observed, and neither subjective symptoms nor clinical signs of TMD correlated significantly with MBF values (14).

Moreover, a correlation between weight and height in male and weight in female TMD subjects occurred (Fig. 1). In a previous study (14), mean MBF values of TMD subjects in molar and incisal regions were reported as significantly higher for male than for female, suggesting that a separate evaluation of the genders would be advisable in future studies involving bite force assessments, which corroborates the results of the present study. Furthermore, bite force was significantly stronger in healthy male than in female (18). The present study also found stronger bite force for males than for females, both in healthy and TMD subjects, echoing the findings from previous studies.

Regarding gender, studies have reported MBF means to be positively correlated in TMD subjects, although the correlation coefficients for age, weight, and height were found to be low (2). The present study, however, found significant correlation in TMD subjects for weight in female and weight and height in male subjects and no correlation for age. Bite force may be significantly associated with gender and age independently of a low bite force, and male subjects should exhibit higher MBF (18). No significant associations between MBF and body mass were found (15), demonstrating that signs and symptoms of TMD, unlike body mass, are independently associated with MBF.

Bite force is reported to decrease with increasing age after 25 years in female and after 45 years in male (20). It also was reported that the direct effect of age on bite force was statistically significant but relatively small between 37 and 80 years (16). In the present study,

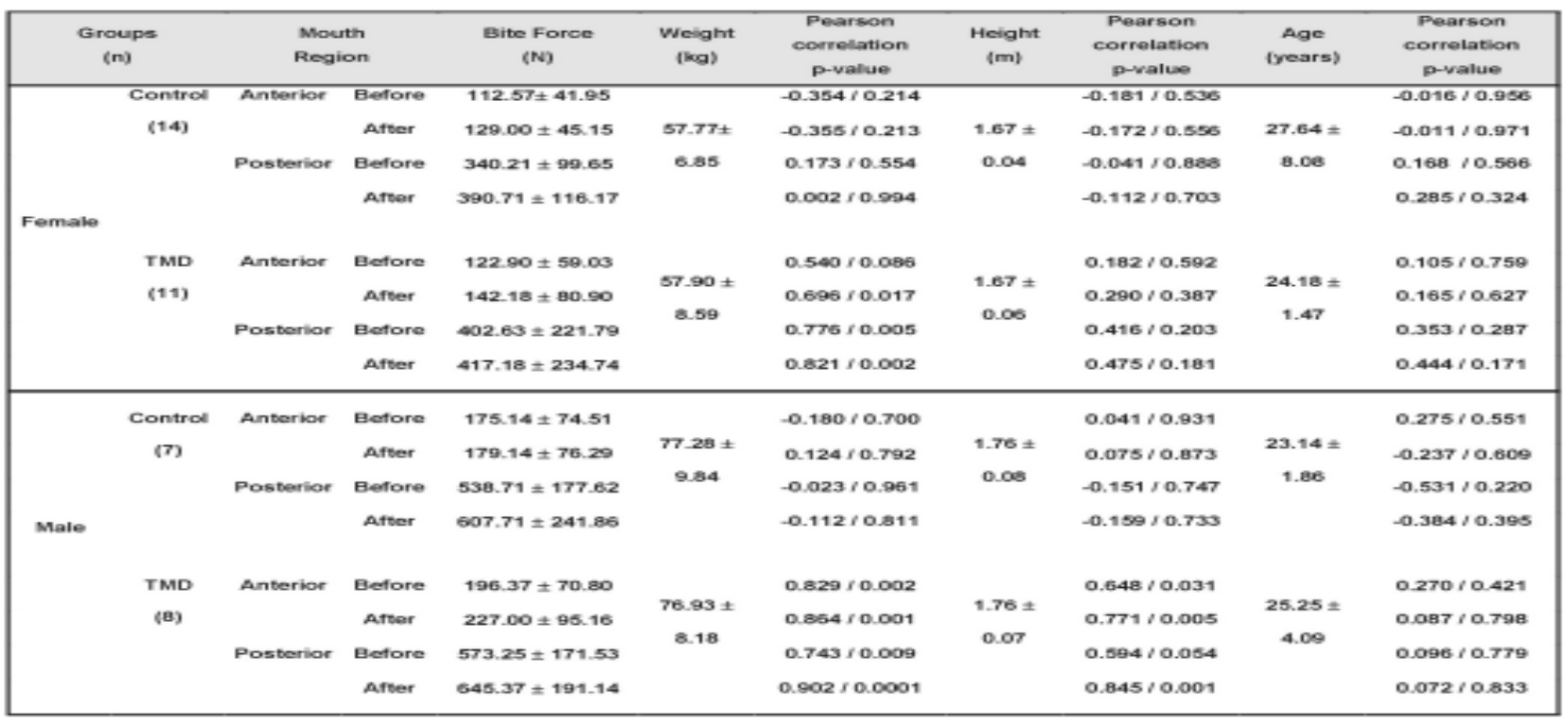

Figure 1. Means, standard deviations for MBF and correlation results with weight, height and age in subjects, considering experimental groups, and mouth region. TMD = temporomandibular disorders. 
there was no significant correlation between age and MBF, probably because of the subjects' low age range. Within the limitations of the present study, it is possible to conclude that the comparison between MBF of TMD and control subjects showed no differences. Moreover, a correlation was found between MBF and weight in both female and male TMD subjects, and between MBF and height in TMD male subjects. These results should be carefully considered because of the difficulties to achieve a number of patients who fulfilled the inclusion criteria. To reach more consistent results, a larger number of patients must be submitted to this evaluation and other aspects, such as masticatory function should be considered.

\section{RESUMO}

Espera-se que indivíduos com desordens temporomandibulares (DTM) tenham diminuição da força máxima de mordida (FMM). Desta forma, este estudo teve como objetivo comparar a FMM em indivíduos com DTM com um grupo controle e também avaliar esta associação com idade, gênero, peso e altura. Quarenta adultos saudáveis com dentição permanente completa foram divididos em 4 grupos de acordo com o gênero, presença ou ausência de sinais/sintomas de DTM (baseado no Research Diagnostic Criteria - RDC) e submetidos a um teste de FMM com um gnatodinamômetro na área de incisivos e molares. A análise estatística foi realizada por meio de análise de variância e StudentNewman-Keuls ( $p=0,05)$, e a relação entre idade, gênero, peso, altura e MBF foi verificada pelo teste de correlação de Pearson. Não houve diferença nos resultados de FMM entre os grupos controle e DTM $(p>0,05)$. As mulheres demonstraram menor FMM que os homens e menor FMM para as áreas anteriores do que para as áreas posteriores ( $\mathrm{p}>0,05)$. Uma correlação significativa foi encontrada entre peso e FMM em indivíduos $\operatorname{com} \operatorname{DTM}(\mathrm{p}<0,05)$, exceto para a área anterior em mulheres. Foi observada uma correlação positiva entre FMM e altura em homens com DTM $(\mathrm{p}<0,05)$. Dentro das limitações deste estudo, é possível concluir que a força de mordida não foi afetada pela DTM. Uma correlação entre FMM e peso em indivíduos com DTM e entre FMM e altura em homens foi evidenciada.

\section{REFERENCES}

1. Sonnesen L, Bakke M, Solow B. Temporomandibular disorders in relation to craniofacial dimensions, head posture and bite force in children selected for orthodontic treatment. Eur J Orthod 2001;23:179-192.

2. Braun S, Bantleon HP, Hnat WP, Freudenthaler JW, Marcotte MR, Johnson BE. A study of bite force, part 1: relationship to various physical characteristics. Angle Orthod 1995;65:367372.

3. Ingervall B, Bitsanis E. A pilot study of the effect of masticatory muscle training on facial growth in long-face children. Eur J Orthod 1987;9:15-23.
4. Shiau YY, Wang JS. The effects of dental condition on hand strength and maximum bite force. Cranio 1993;11:48-54.

5. Sinn DP, de Assis EA, Throckmorton GS. Mandibular excursions and maximum bite forces in patients with temporomandibular joint disorders. J Oral Maxillofac Surg 1996;54:671679.

6. Hagberg C, Hagberg M. Surface EMG frequency dependence on force in the masseter and the anterior temporal muscles. Scand J Dent Res 1988;96:451-456.

7. Dworkin SF, LeResche L. Research diagnostic criteria for temporomandibular disorders: review, criteria, examinations and specifications, critique. J Craniomand Disord 1992;6:301355.

8. LeResche L. Epidemiology of temporomandibular disorders: implications for the investigation of etiologic factors. Crit Rev Oral Biol Med 1997;8:291-305.

9. Tortopidis D, Lyons MF, Baxendale RH, Gilmour WH. The variability of bite force measurement between sessions, in different positions within the dental arch. J Oral Rehabil 1998;25:681-686.

10. Manns A, Miralles R, Palazzi C. EMG, bite force, and elongation of the masseter muscle under isometric voluntary contractions and variations of vertical dimensions. J Prosthet Dent 1979;42:674-682.

11. Kroon GW, Naeije M. Electromyographic evidence of local muscle fatigue in a subgroup of patients with myogenous craniomandibular disorders. Arch Oral Biol 1992;37:215-218.

12. Svensson P, Arendt-Nielsen L, Houe L. Muscle pain modulates mastication: an experimental study in humans. J Orofac Pain 1998;12:7-16.

13. Lyons MF, Baxendale RH. Masseter muscle relaxation rate in volunteers with a myogenous craniomandibular disorder. J Oral Rehabil 1995;22:355-364.

14. Waltimo A, Könönem M. Maximal bite force and its association with signs and symptoms of craniomandibular disorders in young Finnish non-patients. Acta Odontol Scand 1995;53:254-258.

15. Ahlberg JP, Kovero OA, Hurmerinta KA, Zepa I, Nissinen MJ, Kononen MH. Maximal bite force and its association with signs and symptoms of TMD, occlusion, and body mass index in a cohort of young adults. Cranio 2003;21:248-252.

16. Hatch JP, Shinkai RS, Sakai S, Rugh JD, Paunovich ED. Determinants of masticatory performance in dentate adults. Arch Oral Biol 2001;46:641-648.

17. Chandu A, Suvinen TI, Reade PC, Borromeo GL. The effect of an interocclusal appliance on bite force and masseter electromyography in asymptomatic subjects and patients with temporomandibular pain and dysfunction. J Oral Rehabil 2004;31:530-537.

18. Ikebe K, Nokubi T, Morji K, Kashiwagi J, Furuya M. Association of bite force with ageing and occlusal support in older adults. J Dent 2005;33:131-137.

19. Cosme DC, Baldisserotto SM, Canabarro SA, Shinkai RS. Bruxism and voluntary maximal bite force in young dentate adults. Int J Prosthodont 2005;18:328-332.

20. Bakke M, Holm B, Jensen BL, Michler L, Moller E. Unilateral, isometric bite force in 8-68-year-old women and men related to occlusal factors. Scandinavian J Dent Res 1990;98:149-158. 